\title{
As contribuições da economia da confiança para 0 empreendedorismo a partir das tecnologias digitais de comunicação'
}

The contributions of the trust economy to entrepreneurship from digital communication technologies

Las contribuciones de la economía de la confianza al emprendimiento a partir de las tecnologías de comunicación digital

Ramon Bezerra Costa

- Doutor em Comunicação pela Universidade do Estado do Rio de Janeiro (Uerj)

- Mestre em Comunicação pela Uerj

- Professor do Departamento de Comunicação Social e do Programa de Pós-Graduação em Comunicação da Universidade Federal do Maranhão (UFMA)

- E-mail: ramonbzc@gmail.com

\section{Larissa Leda Fonseca Rocha}

- Pesquisadora de pós-doutorado na Escola de Comunicações e Artes da Universidade de São Paulo (ECA/USP), no Centro de Estudos de Telenovela (CETVN)

- Doutora em Comunicação Social pela Pontifícia Universidade Católica do Rio Grande do Sul (PUCRS)

- Mestre em Comunicação Social pela Universidade Federal Fluminense (UFF)

- Professora Adjunta do Departamento de Comunicação Social da UFMA

- E-mail: larissaleda@gmail.com 


\section{Resumo}

A partir de uma pesquisa sobre a chamada economia da confiança, este trabalho tem como objetivo identificar e analisar de que forma seus três eixos - dinâmica entre pares, confiança entre desconhecidos e abundância de recursos - podem orientar a experiência empreendedora contemporaneamente. Apoiando-se em revisão bibliográfica, discutiremos o empreendedorismo atualmente a partir de sua interface com as tecnologias digitais de comunicação.

\section{PALAVRAS-CHAVE: ECONOMIA DA CONFIANÇA•EMPREENDEDORISMO • TECNOLOGIAS DIGITAIS DE COMUNICAÇÃO.}

\section{Abstract}

Based on research on the so-called trust economy, this article aims to identify and analyze how its three axes - peer dynamics, trust between strangers, and abundance of resources - can guide the entrepreneurial experience today. Based on a literature review we will discuss contemporary entrepreneurship from its interface with digital communication technologies.

\section{KEYWORDS: TRUST ECONOMY•ENTREPRENEURSHIP・DIGITAL COMMUNICATION TECHNOLOGIES.}

\section{Resumen}

A partir de una investigación sobre la llamada economía de la confianza, este estudio tiene como objetivo identificar y analizar cómo sus tres ejes (dinámica entre pares, confianza entre extraños y abundancia de recursos) pueden guiar la experiencia emprendedora actualmente. Por medio de una revisión bibliográfica, discutiremos el emprendimiento actual desde su interfaz con las tecnologías digitales de comunicación. 


\section{CONSIDERAÇÕES INICIAIS}

0 s últimos relatórios do Fórum Econômico Mundial (World Economic Forum, 2018) têm indicado que milhares de postos de trabalho poderão ser perdidos por conta da automação, enquanto muitos outros serão criados. É nesse cenário que o empreendedorismo emerge como fenômeno relevante, uma vez que postos de trabalho consolidados parecem perder espaço, enquanto outras funções e necessidades emergem.

Incentivar o empreendedorismo, nesse contexto, especialmente atento às dinâmicas impulsionadas pelas tecnologias digitais de comunicação (TDC), conforme propomos, é um caminho para investir em funções laborais que podem auxiliar na aquisição de mais postos de trabalho. Além disso, o conhecimento e o estímulo a essas dinâmicas empreendedoras podem também auxiliar o poder público na elaboração de políticas públicas para esse cenário.

No entanto, esse ambiente empreendedor é repleto de controvérsias. A mais conhecida, frequente nas coberturas midiáticas, é a precarização do trabalho. A empresa Uber, por exemplo, gerou protestos de taxistas que perderam empregos ou reduziram sua renda, além de queixas de seus condutores quanto ao lucro possível ao trabalhar com a empresa (Fontana, 2019). Scholz (2016) sugere que serviços como esses, sob demanda, realizados por trabalhadores sem direitos garantidos, intensificam o lugar do mercado na vida de todos, configurando o que chama de "capitalismo de plataforma"2.

O empreendedorismo está diretamente relacionado à criação. Não se trata de criar algo ontologicamente novo, mas de inventar arranjos singulares. Assim, essa prática pode ser pensada desde o empreendimento de si, exatamente como a estética da existência tematizada por Foucault (2010), até a criação de produtos e serviços. 0 empreendedorismo pode ser tanto por necessidade (quando não se tem outra oportunidade no mercado de trabalho) quanto por oportunidade (identificação de um mercado a ser explorado). Pode também aprimorar produtos e serviços existentes, como criar novas funcionalidades, até inventar outras formas de comer e de transitar pela cidade. Trata-se de um leque grande de possibilidades, mas o que existe em comum e caracteriza o empreendedorismo é o esforço de expressar uma singularidade. Isso nos lembra a própria noção de inovação. Conforme propõe Callon (2010), inovar é fazer acordos; o fato de uma ideia não ser popularizada não atesta, necessariamente, que era ruim, mas que não existiam condições para sua existência naquele momento - o que não inviabiliza a possibilidade de a ideia ser ruim realmente.

Considerando o empreendedorismo como um esforço de expressão singular, o objetivo deste estudo é identificar e analisar de que forma os três eixos da economia da confiança, conceito oriundo de uma pesquisa realizada entre os anos de 2013 e 2017 (Costa, 2018), podem orientar a experiência empreendedora contemporaneamente. Acredita-se que esses eixos - dinâmica entre pares, confiança entre desconhecidos e abundância de recursos - resumem características centrais dos modos de vida contemporâneos e podem auxiliar na pregnância dos empreendimentos. Deste modo, nos apoiamos em revisão bibliográfica para discutir o empreendedorismo atualmente a partir de sua interface com as TDC, centrais na identificação e estruturação de um ecossistema comunicativo que reorganiza as mais diferentes práticas sociais, desde as ligadas ao comércio e ao trabalho até aquelas relacionadas às possibilidades dos vínculos humanos e sociais. 


\section{O EMPREENDEDORISMO E AS TECNOLOGIAS DIGITAIS DE COMUNICAÇÃO}

O empreendedorismo, em suas diversas expressões, tem emergido de maneira significativa como objeto de debate e estudo em diversas áreas nos últimos anos, apesar de não ser um tema recente. Um dos motivos desse crescimento, falando especificamente da realidade brasileira, parecer ser o aumento da experiência empreendedora no país. A pesquisa Global Entrepreneurship Monitor, realizada em 2018, traz dados que corroboram esse cenário: dois em cada cinco brasileiros entre 18 e 64anos planejavam abrir ou já tinham algum negócio; as taxas de empreendedores "estabelecidos" superou os "iniciais", o que permite considerar que em 2018 os empreendedores antigos puderam consolidar seus negócios criados anteriormente; e o empreendedorismo por oportunidade (quando negócios são criados a partir do reconhecimento de uma oportunidade no mercado) teve o melhor resultado dos últimos quatro anos (Brasil..., 2019).

No entanto, devemos notar que essa importância do empreendedorismo não surge repentinamente. Boltanski e Chiapello (2009) sugerem que desde os anos 1960, no campo empresarial, já existia certa "oferta de libertação", uma espécie de liberdade vigiada permitida somente aos executivos. Nos anos 1990 há uma ampliação disso e as "palavras de ordem são criatividade, reatividade e flexibilidade (Boltanski; Chiapello, 2009, p.121). Sennett (2012) demonstra percepção correlata ao analisar duas gerações diferentes, na figura de um pai, imigrante italiano nos Estados Unidos, e de seu filho, nascido neste país. Para o pai, a função da tarefa laboral era servir a família, com clara separação entre o tempo do trabalho e do lazer (ainda que, não raro, fosse preciso dedicar horas extras ao emprego) e certa segurança e previsibilidade - o pai sabia quando iria se aposentar e quanto sua poupança renderia. A geração do filho, ao contrário, emerge em uma sociedade mais flexível, na qual as relações de trabalho estavam, majoritariamente, marcadas pela instabilidade, pela mudança frequente de emprego, pela inexistência de clareza entre a hora de começar e terminar o trabalho, além de uma busca por satisfação pessoal e profissional. Ou seja, a função da atividade laboral deixa de ser, somente, a subsistência, e agrega uma nova camada: a realização pessoal.

Este cenário descrito por Sennett (2012) nos anos 1990 se intensificou nas décadas seguintes. Castro (2014, p.10), em um trabalho sobre empresas brasileiras criadas, em sua maioria, na primeira década dos anos2000, sugeriu uma espécie de perfil desses empreendedores:

Parecem estar em busca de um trabalho que dê sentido para a vida. Que tem a ver com propósito. Em que podem construir relações com pessoas pelas quais se interessam e admiram. Por isso trocam cargo e estabilidade por motivação, prazer e diversão. Sem jamais abrir mão de reconhecimento. Seus fundadores fazem parte de uma geração que surgiu depois da revolução digital, que tem acesso a um volume enorme de informação, além de ferramentas que possibilitam construir o que desejam. É a geração para a qual tudo é possível. Não faltam conteúdo e instrumentos para construir o que se quer. Sabem usar o conceito de rede tanto para pesquisar assuntos pelos quais se interessam e trocar informações, como para divulgar novas ideias e novos negócios. Também usam a rede para atrair projetos dos quais querem fazer parte e para montar equipes multidisciplinares para trabalhar em cada um deles.

Um aspecto que parece ter contribuído com as experiências empreendedoras descritas por Castro (2014) foi a emergência e a popularização das TDC. Nos últimos 20 anos, presenciamos diversas alterações nas formas de viver influenciadas por elas: a expansão do acesso à internet em dispositivos móveis, o crescente surgimento de softwarese plataformas que favorecem a autonomia dos usuários para publicarem e comercializarem conteúdos e produtos, a redução dos preços de dispositivos como smartphones, entre outras mudanças. Neste contexto, é perceptível também o surgimento e a popularização de relações baseadas na cooperação entre desconhecidos através da internet, como as que deram origem e sustentam a Wikipédia e o Linux.

Tapscott e Williams (2010) analisaram as maneiras pelas quais essas dinâmicas cooperativas podem influenciar os negócios e propuseram quatro ideias que passam a caracterizar os empreendimentos nesse contexto: "abertura", investindo na 
transparência tanto com os funcionários quanto com os públicos, deixando de lado uma espécie de "cultura do segredo"; "peering", isto é, uma forma de organização baseada na horizontalidade em detrimento aos modelos hierárquicos de organização e gestão, permitindo experiências de auto-organização; o "compartilhamento" e a troca entre pessoas, inclusive desconhecidas, que podem inovar com mais eficiência e rapidez, gerando benefícios para os modelos de negócios, o que contraria o pensamento que diz ser necessário controlar e proteger ideias para garantir a inovação; e, por fim, "ação global", ou seja, os negócios se dão em um ambiente global por conta da diminuição das fronteiras devido às TDC e ao melhoramento das condições de transporte, o que permite utilizar recursos, tanto humanos quanto técnicos, nessa escala.

A forma como as TDC alteram as dinâmicas empreendedoras e os modos de funcionamento dos negócios também pode ser percebida em outros estudos. Bauwens etal. (P2P Foundation, 2012) sugerem a emergência da dinâmica da comunidade nos negócios, ou seja, ao contrário de empresas que utilizam estratégias de marketing para atingir consumidores isolados, os atores econômicos atuariam em grupo, entre pares, para gerar valor. 0 autor propõe, ainda, que diante da produção social de valor se dando entre pares nas redes digitais, a propriedade intelectual se torna cada vez mais difícil e improdutiva, criando um cenário propício para o desenvolvimento de modelos de negócios "abertos".

Já Benkler (2004, p.281, tradução nossa) fala sobre a emergência do "compartilhamento como modalidade de produção econômica", que, segundo ele, possui quatro características: são práticas de compartilhamento em grande escala entre indivíduos que são ligados por laços fracos ou são completos desconhecidos; são partilhados bens de propriedade privada; os modelos de negócios utilizam a capacidade ociosa de objetos; e bens rivais ganham outros usos e deixam de rivalizar.

É possível notar, portanto, que a interseção entre as TDC e o cenário dos negócios tem passado por diversas mudanças. É neste contexto que surgem iniciativas empreendedoras baseadas no compartilhamento - em detrimento da posse - de bens e serviços e que têm recebido diversas denominações: consumo colaborativo (Botsman; Rogers, 2011); economia colaborativa (P2P Foundation, 2012), economia do compartilhamento (Rifkin, 2016); wikinomia (Tapscott; Williams, 2010), economia da confiança (Costa, 2018), entre outros. Neste artigo, trabalharemos com a perspectiva da economia da confiança, um processo de vinculação social baseado em três eixos: a dinâmica entre os pares; a confiança entre desconhecidos; e a abundância de recursos.

\section{A ECONOMIA DA CONFIANÇA E SUAS CONTRIBUIÇÕES PARA O CENÁRIO EMPREENDEDOR CONTEMPORÂNEO}

Costa (2018), diante da imprecisão dos diversos termos utilizados para fazer referência às dinâmicas econômicas baseadas no compartilhamento através das TDC, propõe a economia da confiança, entendida não como uma teoria econômica, mas, na esteira do pensamento de Fukuyama (1996), como uma área da sociabilidade humana, uma vez que por meio dela obtemos mais do que recursos financeiros para trocarmos por produtos e serviços, obtemos experiências que dão sentido à nossa existência. 0 que fica explícito no sentido e valor do trabalho para as duas gerações de uma mesma família, observado por Sennett (2012).

A economia da confiança reúne uma diversidade enorme de áreas: alimentação, finanças, hospitalidade, transporte, entre outras. 0 que elas têm em comum é seu modo de funcionamento. São experiências de produção, circulação e consumo, tanto de bens quanto de serviços, baseados em sites ou aplicativos para smartphone e na cooperação entre desconhecidos; acontecendo por meio de relações de troca, empréstimo, doação e aluguel, envolvendo as dimensões on-line off-line (Costa, 2018).

Assim, a economia da confiança diz respeito a 


\section{ANO 16 • NÚMERO 31 • 2º SEM. 2019 • ORGANICOM \\ AS CONTRIBUIÇÕES DA ECONOMIA DA CONFIANÇA PARA O EMPREENDEDORISMO A PARTIR DAS TECNOLOGIAS DIGITAIS DE COMUNICAÇÃO}

um processo de produção, circulação e consumo de bens e serviços que acontece baseado em três eixos: a dinâmica entre pares (que trata do modo de funcionamento); a confiança entre desconhecidos (que funciona como reguladora do processo); e a abundância de recursos (que desempenha o papel de premissa que orienta as ações). Falo em eixos por entendê-los como peças que têm o papel de transmitir o movimento de um lado a outro. Dessa maneira, embora desempenhem funções diferentes, não há hierarquia de importância entre eles e tanto faz a ordem da abordagem. (Costa, 2018, p.68)

Cada um desses eixos foi inspirado em características da sociedade contemporânea que têm relação com as dinâmicas econômicas e, consequentemente, com o empreendedorismo.

Ao tratar do modo de funcionamento, a "dinâmica entre pares" sugere as maneiras como as sociedades contemporâneas parecem se organizar. Questão necessária para as experiências empreendedoras, tendo em vista que elas irão criar formas de acessar produtos e serviços nessa sociedade.

Desde o início da popularização da internet, há cerca de vinte anos, notamos a crescente colaboração em massa entre desconhecidos, que contribuiu com o surgimento do projeto Genoma Humano, por exemplo. 0 que observamos, atualmente, é a cooperação entre estranhos sair do âmbito das ideais e dos conteúdos (como nos exemplos citados) e chegar ao "mundo real", ou "mundo off-line", e afetar outras indústrias. Foram criados empreendimentos a partir dos quais as pessoas passaram a compartilhar roupas, hospedagem, comida, bicicletas, passeios.

A dinâmica entre pares da economia da confiança torna viável outras formas de conexão entre pessoas e coisas. Em vez de comprar uma frota de automóveis para criar uma empresa de aluguel de carros, por exemplo, foram criadas plataformas diversas. As mais conhecidas permitem dirigir seu próprio carro, ou um alugado, fazendo transporte privado de passageiros. A complexa dinâmica da mobilidade urbana em cidades de médio e grande porte também permitiu soluções só possíveis a partir dessa nova dinâmica: em algumas é possível alugar os seus carros para desconhecidos quando você não estiver usando; em outras você pode oferecer e/ou pegar carona com alguém que faça o mesmo trajeto que o seu.

Baseado na conexão entre pares, também têm surgido iniciativas empreendedoras da área da hospitalidade que não constroem prédios com vários andares e quartos, mas conectam pessoas com espaços ociosos a outras que precisam de estadia. E não somente a conhecida Airbnb, que trabalha com a política do pagamento pela hospedagem, mas iniciativas que não cobram pela estadia e outras voltadas a públicos com interesses específicos, como as que permitem trocar estadia por trabalho e as que visam pessoas que viajam de bicicleta.

Cabe ressaltar que falar em modelos produtivos baseados no compartilhamento e em ampliação das possibilidades de cooperação não significa sugerir que sejam modelos melhores ou piores. Exemplo disso é a Uber, que no intervalo de um ano alterou a porcentagem descontada de cada motorista, que passaram a precisar trabalhar mais horas (Machado, 2019), ou a Airbnb, que tem sido apontada como responsável pelo aumento do aluguel em algumas cidades, fazendo com que os antigos inquilinos precisassem mudar para locais distantes do centro, por exemplo (van der Zee, 2016). 0 importante é notar as conexões possíveis, como elas têm se ampliado nos últimos anos e seu papel na emergência de iniciativas empreendedoras.

A partir da expansão da computação móvel e da ampliação do acesso à internet via banda larga, cooperar com o outro passa a ser "mais viável" ou "mais fácil". Assim, surgem e consolidam-se outros mediadores, como as empresas citadas. Devemos ter cuidado para não emitir juízo de valor e entender que tais modelos sejam melhores ou piores do que outros existentes, como os taxis e hotéis, por exemplo. Ambos têm elementos que podem ser apontados como benéficos ou não, mas este não é o foco deste trabalho. 
A tendência é que a conexão entre pessoas e coisas se torne cada vez mais generalizada. 0 conceito de Internet das Coisas sugere isso. Santaella (2013, p.31) descreve esse ambiente:

Daqui a muito pouco tempo, os microchips se tornarão tão abundantes que sistemas inteligentes serão espalhados aos milhões em todo canto de nosso ambiente, incorporados às paredes, aos móveis, aos nossos aparelhos, nossa casa, nosso carro, penetrando na estrutura de nossas vidas. Os ambientes irão se tornar inteligentes, transformando tudo à nossa volta. Tal panorama anuncia a "internet das coisas", que se define como a extensão da internet no mundo físico, tornando possível a interação com objetos e a comunicação autônoma entre objetos.

Não podemos esquecer que essa conexão generalizada e o tipo de experiência de convergência e de integração entre pessoas e objetos, que a Internet das Coisas parece implicar, não ocorre sem conflitos, a exemplo da instauração de modelos produtivos baseados no compartilhamento. Estes modelos reduzem a privacidade e ampliam a possibilidade de invasão a dados pessoais. Este aspecto, ainda que não seja aprofundado aqui, deve ser considerado no intuito de evitar interpretações da dinâmica entre pares como um processo exclusivamente positivo e harmonioso.

A Internet das Coisas é para onde parece levar a dinâmica entre pares, com cada vez mais pessoas e dispositivos conectados. Podemos entendê-la a partir de Rifkin (2016, p.25):

A Internet das Coisas (IdC) irá conectar todas as coisas com todo o mundo numa rede global integrada. Pessoas, máquinas, recursos naturais, linhas de produção, hábitos de consumo, fluxo de reciclagem e praticamente todo e qualquer aspecto da vida econômica e social estará conectado via sensores e software à plataforma IdC, alimentando continuamente cada nó empresas, lares, veículos - com Big Data (megadados), minuto a minuto, em tempo real.

Diante disso, a primeira contribuição da economia da confiança para o empreendedorismo é compreender que nossas sociedades estão cada vez mais organizadas entre pares, ou seja, nossas possibilidades de interação, seja para conversar ou vender produtos, por exemplo, se ampliam e permitem a emergência das mais singulares expressões do empreendedorismo.

Nesse cenário de conexão entre pares surge a necessidade de construir a confiança entre eles. Como defende Simmel (2004), a confiança entre as pessoas é um elemento fundamental para a integração da sociedade. Rifkin (2012, p.54) evidencia como a confiança é primordial nas relações econômicas:

A economia envolve sempre um jogo de confiança. Costumávamos pensar que o comércio e as transações comerciais fossem respaldadas pelo ouro ou pela prata, mas na realidade estes sempre foram lastreados por uma reserva mais importante - a confiança pública. Quando essa confiança é forte, a economia floresce e o futuro nos move. Quando a confiança pública é abalada, as economias fracassam e o futuro torna-se sombrio.

Giddens (1991) entende a confiança como uma ação consciente de acreditar em algo considerando as possíveis situações de risco. Trata-se de uma espécie de risco calculado que tenta antever os perigos para que a confiança seja construída. Por exemplo: andar em veículos automotores possui riscos, como colisões e explosões, mas existem aparatos (regras de trânsito e itens de segurança, por exemplo) para reduzir as possibilidades disso acontecer.

Quando pensamos a construção da confiança na internet podemos observar um processo paulatino. Inicialmente, após questionar se as pessoas com quem conversávamos por bate-papo eram reais, começamos a fazer compras, primeiramente em lojas conhecidas e depois de desconhecidos em sites como o Mercado Livre. Atualmente, estamos nos hospedando 
na casa de desconhecidos (sites como Airbnb, pago, e Couchsurfing, gratuito, são exemplos) e pegando caronas com estranhos (em plataformas como a Blablacar). Mas como se deu esse processo?

Castells (2013, p.7) considera que a confiança parece estar diminuindo nas sociedades.

A confiança desvaneceu-se. E a confiança é o que aglutina a sociedade, o mercado e as instituições. Sem confiança nada funciona. Sem confiança o contrato social se dissolve e as pessoas desaparecem, ao se transformarem em indivíduos defensivos lutando pela sobrevivência.

A crescente desconfiança indicada pelo autor é corroborada pela pesquisa Trust Barometer, realizada anualmente pela agência de relações públicas Edelman. Segundo Richard Edelman, CEO da empresa, a última década tem sido caracterizada pela desconfiança crescente em figuras de autoridade tradicional, como a mídia e os governos (Arcoverde, 2019).

Pode parecer estranho surgirem empreendimentos que constroem a confiança de outra forma nesse cenário, mas talvez eles sejam menos um indicativo de estranheza e mais uma evidência da necessidade de outros parâmetros para elaborar e validar a confiança. Nas iniciativas da economia da confiança, independentemente da área, a estratégia mais comum de construção da confiança são as referências e comentários que as pessoas deixam nos perfis das outras após cada transação. É como as avaliações de produtos em lojas on-line ou os comentários nos sites de notícias. Mas que, no caso, é uma condição de possibilidade dos empreendimentos. É possível, como alternativa a um restaurante famoso durante uma viagem, ser recebido por moradores locais para a refeição (sites como Eatwith e Mealsharing, por exemplo, permitem isso) ou comprar as sobras do jantar de uma família (A comida da vizinha é uma plataforma que oferece esse serviço), mas tais serviços só são validados a partir da construção da reputação produzida pelos comentários de outras pessoas.

0 fato é que estamos realizando mais transações com desconhecidos e isso tem permitido a emergência de empreendimentos baseados nessas outras formas de construir a confiança. É possível afirmar, que diante da desconfiança nas grandes e tradicionais instituições e da possibilidade de nos conectarmos entre pares por conta das TDC, surge um ecossistema favorável aos empreendimentos que conectam estranhos e constroem a confiança entre eles, não pelo seu tempo no mercado, mas pelos comentários que outras pessoas, também desconhecidas, deixaram em seus perfis nas plataformas. Isso cria um ambiente que pode ser explorado visando a criação de modelos de negócios baseados na transparência entre os pares desconhecidos.

O surgimento de pessoas não profissionais que oferecem serviços nas horas vagas, bem como a utilização de bens que estariam ociosos deixam evidente uma mudança de cenário que se torna possível a partir do encontro entre a dinâmica de conexão e a possibilidade da confiança entre desconhecidos. Exemplos são pessoas que oferecem jantar em sua casa e ganham uma renda extra com isso, mas exercem suas atividades laborais em outras áreas; ou outras que permitem o uso de seus bens, como o quarto dos filhos que casaram e deixaram o espaço vazio na casa ou o carro que só é usado algumas vezes na semana ou que fica durante oitohoras por dia parado no estacionamento enquanto seu proprietário trabalha são referências de potenciais ativos que ganham uso quando tal encontro entre conexão e confiança acontece.

Embora a tradição econômica, majoritariamente, entenda os bens como escassos, como é evidente no trabalho de Robbins (1945), em uma das primeiras e ainda mais aceitas definições contemporâneas de economia, observamos atualmente a possiblidade da abundância. Aprendemos a lidar com a abundância quando se trata de bens imateriais (também chamados de não rivais), como músicas e filmes que se "libertaram" do suporte material permitindo que várias pessoas tenham 0 mesmo produto sem que isso impeça que o outro também o tenha, como Rifkin (2001) indicou no início dos anos 2000. 
O que notamos hoje é a mesma abundância dos bens imateriais chegarem aos bens rivais. Isso não significa que os objetos físicos, como um ferro de passar roupa, possam ser desmaterializados e multiplicados, mas que outras formas de se ter acesso a eles estão surgindo. Raramente alguém usa o ferro de passar todos os dias, então ele não poderia ser utilizado por um(a) vizinho(a) nos outros dias? 0 mesmo pode ser considerado para qualquer objeto subutilizado por alguém. Um problema imediato, sobretudo nas grandes cidades, é o fato de não conhecermos quem mora ao nosso lado. Para isso que surgem aplicativos como o Tem açúcar?, que utiliza o GPS e coloca em contato quem precisa de algo com a pessoa que pode emprestar aquilo. 0 mesmo vale para serviços em plataformas como o Timerepublik, que conecta pessoas dispostas a ensinar, por meio de troca, habilidades umas às outras.

Para Diamandis e Kotler (2012, p.289): "a abundância é tanto um plano como uma perspectiva". Assim, diz respeito a uma forma de gerir e se relacionar com bens e serviços. É perceber utilidade onde existiria ociosidade. Nesse cenário, o valor será construído de outra maneira.

O valor vai emergir nesta nova economia da capacidade de conectar perfis a informações, a ações e a outras perfis, liberando-as para compartilhar todo o tipo de conteúdo na rede. No velho paradigma dos portais, só havia valor se os meios de comunicação social escasseassem. No paradigma do compartilhamento livestream, ao alimentar a criação de novos perfis, o valor reside na quantidade de interações geradas e na socialização dos conteúdos. (Malini; Antoun, 2013, p.215)

Apesar de abordarem a produção de conteúdo, Malini e Antoun (2013) indicam como o valor é construído no cenário de abundância a partir da conexão entre pares, que pressupõe, na perspectiva defendida aqui, a confiança entre desconhecidos.

Assim, a percepção da abundância permite que serviços sejam criados, ou seja, não só é possível como desejável empreender a partir da observância de que há um negócio onde aparentemente não existiria. Trata-se de uma otimização de recursos que pode reduzir custos e desperdícios.

\section{CONSIDERAÇÕES FINAIS}

Neste estudo, refletimos sobre características que podem orientar o empreendedorismo contemporaneamente. Fizemos isso a partir dos três eixos da economia da confiança. 0 primeiro deles, a dinâmica entre pares, nos convida a perceber a sociedade cada vez mais organizada por meio de outros mediadores que unicamente criam ecossistemas interativos e permitem uma conexão direta entre pessoas desconhecidas para que possam acessar, de diferentes formas, produtos e serviços. Esse ambiente, para que possa funcionar, requer outro eixo: a confiança entre estranhos, geralmente construída entre os próprios pares desconhecidos por meio de comentários e referências. Contudo, essas dinâmicas só operam por conta de uma mudança na perceção dos recursos: eles não são escassos, mas abundantes por conta de outras formas de gestão dos bens e serviços - o terceiro eixo da economia da confiança.

Nesse contexto, a propriedade individual parece, gradativamente, estar cedendo espaço ao acesso compartilhado. Isso não significa que deixaremos de possuir bens, caso contrário não seria possível compartilhá-los. 0 que emerge são outros valores e crenças que organizam nossa perceção e ação no mundo.

A organização da vida contemporânea em megacidades, como São Paulo, que soma uma população estimada, em 2018 (IBGE..., 2019), de mais de 12 milhões de habitantes, produz estranhezas como morar em condomínios densamente povoados, estar conectado a milhares de pessoas nas redes sociais digitais, mas não conhecer o vizinho com quem se divide a parede da sala. As TDC são, ao mesmo tempo, resultado e promoção de outros modos de estar juntos, produzir e consumir em 
um ecossistema comunicativo e social em profundas transformações. Sua observação, análise e compreensão só podem ser provisórias, sob risco de serem invalidadas por um tempo que não para, muda estatutos antes estáveis - como a ideia de confiança - e corre cada vez mais rápido.

Tal ecossistema nos oferece mudanças que impactam diretamente na organização do trabalho que ameaça ou decreta o fim de postos já consolidados - como o dos motoristas profissionais de táxis - e faz aflorar diferentes maneiras de participar do processo produtivo. Ainda que tudo que possamos falar sobre este momento deva ser dito com cautela, é possível, desde já, entender que nesse cenário o empreendedorismo se mostra como um fenômeno relevante e digno tanto de atenção, quanto de compreensão em sua mudança, com funções e necessidades despontando sem parar.

Em um cenário de diversos desordenamentos, é essencial voltar nossa atenção tanto para a identificação desses empreendimentos que nascem na economia da confiança - impulsionadas pelas TDC - quanto para sua compreensão e complexificação. Se plataformas como o Tem açúcar? permitem tanto criar maiores conexões entre pessoas desconhecidas, quanto resolver grandes ou pequenos problemas cotidianos - como perceber que não há ovos suficientes para a receita de bolo que ia fazer - são capazes, pelo exemplo, de apontar caminhos alternativos por onde o empreendedorismo pode dirigir-se em um contexto no qual atores sociais clássicos - como a publicidade - perdem lentamente seu poder legitimador, enquanto outros - pessoas comuns - veem valorizado seu lugar de fala como atribuidor de valor simbólico e econômico. Não é possível negar que hoje confiamos em desconhecidos - seja para nos levar de um ponto a outro da cidade, emprestar um punhado de feijão ou nos hospedar em uma viagem - e entender isto com um olhar sobre o empreendedorismo abre a possibilidade da sofisticação de formas de construir a confiança e, também, de construir negócios.

\section{REFERÊNCIAS}

ARCOVERDE, Letícia. Brasileiros confiam mais no empregador do que no governo e no mercado. Valor Econômico, São Paulo, 21 jan. 2019. Disponível em: https://glo.bo/2DpliPj. Acesso em: 30 jul. 2019.

BENKLER, Yochai. Sharing Nicely: on shareable goods and the emergence of sharing as a modality of economic production. The Yale Law Journal, New Haven, v.114, p.273-358, 2004.

BOLTANSKI, Luc; CHIAPELLO, Ève. O novo espírito do capitalismo. São Paulo: WMF Martins Fontes, 2009.

BOTSMAN, Rachel; ROGERS, Roo. O que é meu é seu: como o consumo colaborativo vai mudar o nosso mundo. Porto Alegre: Bookman, 2011.

BRASIL teve 2ํㅜ melhor desempenho em empreendedorismo em 2018. Agência Brasil, Brasília, DF, 26 fev. 2019. Disponível em: https://bit.ly/20J9Vt2. Acesso em: 23 set. 2019.

CALLON, Michel. Por uma nova abordagem da ciência, da inovação e do mercado: o papel das redes sociotécnicas. In: PARENTE, André (org.). Tramas da rede: novas dimensões filosóficas, estéticas e políticas da comunicação. Porto Alegre: Sulina, 2010. p.64-79.

CASTELLS, Manuel. Redes de indignação e esperança: movimentos sociais na era da internet. Rio de Janeiro: Zahar, 2013. 
CASTRO, Mariana. Empreendedorismo criativo: como a nova geração de empreendedores brasileiros está revolucionando a forma de pensar conhecimento, criatividade e inovação. São Paulo: Portfolio-Penguin, 2014.

COSTA, Ramon Bezerra. Economia da confiança: comunicação, tecnologia e vinculação social. Curitiba: Appris, 2018.

DIAMANDIS, Peter H.; KOTLER, Steven. Abundância: o futuro é melhor do que você imagina. São Paulo: HSM, 2012.

FONTANA, Guilherme. Motoristas de aplicativos Uber e 99 fazem greve por lucros maiores. G1, [s.l.], 8 maio 2019. Disponível em: https://glo.bo/20Q9WeU. Acesso em: 24 jul. 2019.

FOUCAULT, Michel. Ética, sexualidade, política. Rio de Janeiro: Forense Universitária, 2010. (Coleção Ditos e Escritos,5).

FUKUYAMA, Francis. Confiança: as virtudes sociais e a criação da prosperidade. Rio de Janeiro: Rocco, 1996

GIDDENS, Anthony. As consequências da modernidade. São Paulo: Ed. Unesp, 1991.

IBGE | Cidades@ | São Paulo | São Paulo | Panorama. IBGE, Rio de Janeiro, 2019. Disponível em: https://bit.ly/2XZKcB8. Acesso em: 21 jul. 2019.

MACHADO, Leandro. Dormir na rua, pedalar $30 \mathrm{~km}$ e trabalhar $12 \mathrm{horas}$ por dia: a rotina dos entregadores de aplicativos. BBC News Brasil, São Paulo, 22 maio 2019. Disponível em: https://bit.ly/2Dou5n1. Acesso em: 21 jul. 2019.

MALINI, Fábio; ANTOUN, Henrique. A internet e a rua: ciberativismo e mobilização nas redes sociais. Porto Alegre: Sulina, 2013.

P2P FOUNDATION. Synthetic overview of the collaborative economy. [Amsterdam]: P2P Foundation: Orange Labs, 2012.

RIFKIN, Jeremy. A era do acesso. São Paulo: Makron Books, 2001.

RIFKIN, Jeremy. A Terceira Revolução Industrial: como o poder lateral está transformando a energia, a economia e 0 mundo. São Paulo: Makron Books, 2012.

RIFKIN, Jeremy. Sociedade com custo marginal zero: a internet das coisas, os bens comuns colaborativos e o eclipse do capitalismo. São Paulo: Makron Books, 2016.

ROBBINS, Lionel. An essay on the nature and significance of economic science. London: Macmillan, 1945.

SANTAELLA, Lucia. Comunicação ubíqua: repercussões na cultura e na educação. São Paulo: Paulus, 2013.

SCHOLZ, Trebor. Platform cooperativism: challenging the corporate sharing economy. New York: Rosa Luxemburg Stiftung, 2016.

SENNETT, Richard. A corrosão do caráter. consequências pessoais do trabalho no novo capitalismo. Rio de Janeiro: Record, 2012.

SIMMEL, Georg. The philosophy of money. London: Routledge, 2004. 
TAPSCOTT, Don; WILLIAMS, Anthony D. Wikinomics: how the mass collaboration changes everything. [New York]: PortfolioPenguin, 2010.

VAN DER ZEE, Renate. The 'Airbnb effect': is it real, and what is it doing to a city like Amsterdam? The Guardian, Amsterdam, 6 Oct. 2016. Disponível em: https://bit.ly/35JbYEt. Acesso em: 21 jul. 2019.

WORLD ECONOMIC FORUM. Towards a Reskilling Revolution: a future of jobs for all. Genève: WEF, 2018.

Artigo recebido em 31.07.2019 e aprovado em 25.11.2019. 